\title{
PRIVAÇÃO AFETIVA E SUAS CONSEQUÊNCIAS NA PRIMEIRA INFÂNCIA: UM ESTUDO DE CASO
}

\section{AFFECTIVE DEPRIVATION AND ITS CONSEQUENCES IN EARLY CHILDHOOD: A CASE STUDY}

Recebido em: 20/05/2018. Aceito em: 18/10/2018.

Daniele Barbosa Rayane ${ }^{1}$ Daniela Heitzmann Amaral Valentim de Sousa ${ }^{2}$

\section{RESUMO}

O presente estudo teve por objetivo investigar os possíveis danos emocionais e psicossociais causados a uma criança que sofreu privação afetiva na primeira infância e que está em situação de acolhimento institucional. Para tanto, baseando-se em fundamentos teóricos psicanalíticos, foi realizado um estudo de caso de natureza qualitativa com uma criança de 8 anos de idade, do sexo feminino acolhida há 2 anos na Instituição de Acolhimento. Os instrumentos utilizados foram um questionário sociodemográfico, uma entrevista semiestruturada, e a aplicação dos testes projetivos O Desenho da Família (2003), e a Fábula de Duss (1986). A análise dos dados evidenciou conflitos em todas as fases do desenvolvimento infantil, confirmando a privação afetiva exérienciada no seu núcleo familiar em que, de acordo com os resultados obtidos, se identifica que a privação de afeto vivida pela infante na primeira infância trouxe prejuízos em vários aspectos do seu desenvolvimento, tendo destaque o cognitivo, o emocional e o social. Sendo assim, se conclui que a má qualidade das relações afetivas na primeira infância pode causar danos e prejuízos ao desenvolvimento emocional e psicossocial da criança.

Palavras-chave: Privação afetiva. Consequências. Primeira infância.

\section{ABSTRACT}

The present study aimed to investigate the possible emotional and psychosocial damages caused to a child who suffered affective deprivation in early childhood and

1Graduada em Psicologia pelo Centro Universitário de João Pessoa (UNIPÊ) e pós-graduanda em Teoria da Psicanálise. E-mail: danny.rayane@gmail.com

2 Doutora em Psicologia Social pela Universidade Federal da Paraíba (UFPB). Docente do Centro Universitário de João Pessoa (UNIPÊ) e das Faculdades de Enfermagem e Medicina Nova Esperança. E-mail: danihapsi@yahoo.com.br 
who is in an institutional reception situation. To do so, based on psychoanalytical theoretical foundations, a case study of a qualitative nature was carried out with an 8-year-old female, who was received at the Institution two years ago. The instruments used were a sociodemographic questionnaire, a semi-structured interview, and the application of the projective tests Family Drawing (2003), and Fábula de Duss (1986). Data analysis revealed conflict at all stages of the child's development, confirming the affective deprivation experienced in the family nucleus where, according to the results obtained, it is identified that the deprivation of affection experienced by the child in early childhood brought losses in Aspects of their development, with emphasis on cognitive, emotional and social aspects. Therefore, it is concluded that the poor quality of the affective relations in the infancy can cause damages and losses to the emotional and psychosocial development of the child.

Keywords: Affective deprivation. Consequences. Early childhood.

\section{INTRODUÇÃO}

O presente estudo visou analisar, em um estudo de caso, as consequências emocionais decorrentes da privação afetiva com uma criança em situação de acolhimento institucional. Consequências essas, causadas devido à má qualidade da relação efetiva dos genitores para com a infante na primeira infância, ou até mesmo pela falta total desta.

Estudiosos da área, como psicólogos e sociólogos, defendem que a primeira infância, de 0 a 6 anos de idade, é primordial para o desenvolvimento da criança, no qual arquitetará uma base que a favorecerá por toda sua existência (UNESCO, 2007), é nesse período do desenvolvimento que quase todas as células do cérebro são formadas, assim como destaca relatório da UNISEF (2001), sendo essas as responsáveis pela elaboração das emoções, da cognição e das relações psicossociais. Nesse sentido, uma boa formação ocorre quando existem estímulos positivos vindos dos cuidadores que, favorecem o crescimento e o amadurecimento das crianças.

Sendo a primeira infância uma fase delicada, e porque não dizer decisiva, no processo de desenvolvimento do ser humano, há destaque para a relação parental paterna e principalmente materna, com elevada significância para que todos os campos de maturação sejam bem elaborados e estruturados.

Como enfatiza Benhaim (2008), a mãe é responsável pela estruturação psíquica da criança nos seus primeiros anos de vida, e que vão sendo construídas através das relações estabelecidas com o seu filho. Assegurando cuidados e proteção ao longo do seu crescimento favorecendo um desenvolvimento saudável.

Pode-se citar também que a aprendizagem, o desenvolvimento cognitivo e as emoções de uma criança começam a ser experenciadas e organizadas nos primeiros dias de vida, em que o bebê ainda não tem noção do seu próprio self. É nessa relação de 
carinho, afeto, e confiança que o bebê meses depois passa a ter consciência de mundo e descobre que ele e sua mãe não são mais um só (BOWLBY, 2006).

A privação afetiva ocorrida nesse período poderá gerar a perda de referências identificatórias causando possíveis conflitos internos e externos, citado por Gomide (2009, p. 73), como, por exemplo, "a negligência impede o desenvolvimento da autoestima, que é o principal antídoto ao aparecimento do comportamento antissocial. A criança negligenciada é insegura, seu olhar não tem brilho. Por não ter recebido o afeto que alimentaria seu ser”, ela se torna frágil.

Bowlby (2006), destaca que as frustrações são realmente significativas para as crianças, estando relacionada às necessidades que elas têm de atenção e de amor por parte dos seus pais (ou de quem efetive essa função) que são exercidas durante os cuidados básicos, a exemplo da alimentação, higiene e da educação, por isso sua falta são desestabilizadoras, porque estão relacionadas ao afeto recebido durante a interação com os genitores além de serem básicas para a sobrevivência do bebê.

Observa-se que esse tipo de conduta para com as crianças pode atingir famílias de todas as classes sociais, e nem sempre tem a ver com a vontade da mulher em ter aquele filho, mas pelo simples fato de não conseguir ser uma mãe suficientemente boa (WINNICOTT, 1956, 2012). Nesse ponto surge a necessidade de se distinguir Maternidade de Maternagem, em que a primeira pode ser vista como uma condição física, biológica em se poder gerar um bebê. Por sua vez, a segunda, a Maternagem, é um estado de amor, de carinho e de afeto direcionados a criança, estabelecendo um vínculo com a mesma (WINNICOTT, 1958, 2000).

Diversas são as consequências causadas pela falta desse vínculo afetivo nos primeiros 6 anos de vida da criança, principalmente nos aspectos cognitivo e afetivo. Os abalos emocionais diante das privações vividas podem causar à criança um transtorno de conduta, psicose e até mesmo a depressão.

De acordo com o manual de Psiquiatria Infantil Ajuriaguerra e Marcelli (1998), a psicose na infância é um transtorno de personalidade em que se destaca pela relação da criança como meio ambiente, e com o seu próprio eu. Dando destaque à algumas características que são apresentadas por crianças que possuem esse transtorno, como: Dificuldades de se expressar e na linguagem, alterações visíveis nas habilidades espaciais, no ritmo e na altura, tem dificuldades em entender aquilo que ver, sua verbalização é estereotipada, possuindo um comportamento social diferente e geralmente isolado. Todas essas consequências podem ser causas de uma possível privação de afeto parental nesta fase do desenvolvimento.

\section{PRIVAÇÃO AFETIVA, DO QUE ESTAMOS FALANDO?}

A família é fundamental para o desenvolvimento emocional e psicossocial da criança. Quando uma criança nasce, ela precisa de alguém que a ajude a construir uma boa formação psíquica (pessoas identificatórias) que as proporcione muito além 
de cuidados básicos, mas, que exista uma relação de carinho e afeto advindas desses cuidados. É através desse contato que se inicia as relações emocionais e psicossociais do sujeito.

Quando essa relação e vinculação não são estabelecidas, a criança passa por um processo nomeado por Winnicott $(1956,2012)$, de privação e deprivação. A privação acontece por volta de zero a seis meses de idade no qual o bebê tem a dependência absoluta da mãe, é um ser onipotente e possui a fixação que os dois são um só. A mãe, quando passa a inserir falhas que a criança ainda não é capaz de elaborar, dependendo do contexto em que ela acontece, poderá surgir futuramente uma criança psicótica. Já a deprivação, é a dependência relativa da mãe, em que a criança já consegue diferenciar o Eu do Tu, ou seja, que ele e a sua mãe são pessoas distintas, fato que ocorre dos seis meses aos dois anos de idade. Nesse período a criança já passou pela fase da total dependência, mas se a sua cuidadora voltar a inserir falhas contínuas, a criança vai direcionar toda a sua angustia, carência e falta de cuidados adequados dessa mãe para o ambiente, podendo se tornar uma criança agressiva e destrutiva. Assim, a criança expõe no comportamento antissocial sua tentativa de recuperar todo o afeto e atenção que um dia lhes foi tirado.

Ou seja, a negligência parental ocorrida pela privação pode ser caracterizada pela falta ou interrupção de uma relação estabelecida entre uma criança e seus cuidadores primários. Pode-se destacar que a falta de estímulos básicos considerados necessários para um desenvolvimento saudável, é uma das formas mais severas de negligencia pelo abandono total da criança, no qual poderá gerar consequências que o acompanhará por toda sua vida.

A fase que será determinante nesse processo é denominada de primeira infância. De acordo com Freud (1905, 1996), em seu Ensaio sobre a Teoria da Sexualidade Humana, a primeira infância acontece de zero a seis anos de idade, fase que inicia o desenvolvimento psicossexual e emocional da criança, sendo primordial para um crescimento saudável e determinante para a vida adulta do sujeito.

Essa é a fase em que a criança inicia a estruturação do seu "Eu" a partir das relações construídas com os seus cuidados primários, efetivados por sua mãe e seu pai. Essa relação de apego tem início desde a gestação da mãe, em que a mesma passa a perceber o bebê como extensão do seu corpo, criando um vínculo de carinho, de afeto e de cuidado. A princípio o bebê sente como se fizesse parte da mãe e é com o passar do tempo que ele vai tomando consciência do seu próprio eu e do mundo (BOWLBY, 2006). Apesar desses vínculos parentais serem de extrema importância, é fácil encontrar hoje crianças que apresentam dificuldades em vários campos do seu desenvolvimento pela falha desses cuidados básicos e necessários.

Esse exercício parental demanda uma série de responsabilidades, habilidades e tarefas, que vão se transformando de acordo com o desenvolvimento da criança e que são essenciais na estruturação da personalidade dos indivíduos, pois a dimensão da sexualidade na infância se refere a sua relação direta com a afetividade estabelecida 
entre as crianças e seus cuidadores (BORGES, 2005). Em “Três ensaios de sexualidade" de Freud $(1905,1996)$, é relatado que a sexualidade tem início desde os primeiros anos de vida. A excitação e a erotização estão relacionadas à natureza humana, sendo elas situadas em algumas partes do corpo (zonas erógenas), formando os estágios do desenvolvimento que são diferenciados.

Dessa maneira, se tem: a fase oral (de zero a seis meses) a zona de prazer da criança é situada na boca e na língua, através da amamentação, do sugar, entre outras; a fase anal (de seis meses a três anos) a sua zona erótica é o ânus que são o amadurecimento neurofisiológico; a fase fálica (três a seis anos) em que a libido está voltada para a zona genital, fase que ocorre o complexo de Édipo. A latência (seis a onze anos) é um período em que a libido não está direcionada para o próprio corpo como nas fases anteriores, sua atividade sexual é reprimida, pois agora a criança está voltada para atividades externas e para o convívio social. Com o término da latência se inicia a puberdade, em que o prazer passa a ser procurado no outro, e não somente no seu próprio corpo como era na infância (FREUD, 1905, 1996).

Para que todas essas fases da primeira infância supracitadas sejam vivenciadas de forma saudável, é necessário que os pais ou os cuidadores realizem sua função adequadamente nesses estágios através da vinculação afetiva inicial, sendo essa uma condição necessária para que o indivíduo se constitua psiquicamente de forma saudável. Porém, quando essa relação não é estabelecida, quando há falhas e a criança é privada dos cuidados básico e principalmente desse vinculo de amor e de segurança ela passa a sofrer a privação afetiva (WINNICOTT, 1956, 2012).

A "privação de mãe" acontece quando a criança é impedida de experienciar os cuidados e afeto que são proporcionados por essa relação. Esses rompimentos podem ocorrer de diferentes formas, como na privação parcial, em que a criança ainda tem contato com a mãe, mas não recebe os carinhos adequados, como cuidados básicos, afeto e amor. Já na privação total, a criança não tem mais vínculos parentais, sendo separada tanto fisicamente como emocionalmente (BOLWBY, 2006). Esse rompimento apresentado por Gomide (2009), se dar por diversos motivos, seja ele por rejeição, separação do casal parental, morte, indiferença ou impaciência por parte da mãe ou dos seus cuidadores. Sendo assim, nem sempre a privação acontece pela falta da presença das figuras parentais, ou dos seus familiares, mas pela falta de uma boa relação afetiva advindas dessas pessoas para com a criança. Essa quebra de vínculos poderá gerar várias consequências na primeira infância, perpassando por toda a vida do sujeito no qual serão destacados no próximo tópico.

\section{CONSEQUÊNCIAS DA PRIVAÇÃO AFETIVA}

A primeira relação experienciada da criança quando nasce é através dos seus cuidadores primários, a figura materna e paterna, e é através dessa relação que se inicia sua estruturação psíquica, emocional e o desenvolvimento da personalidade do sujeito. 
Quando essa estrutura familiar é disfuncional não atuando de maneira saudável ou satisfatória a criança não terá estímulos suficientes para um amadurecimento emocional e nem para um desenvolvimento satisfatório.

Pode-se destacar que várias dificuldades são apresentadas por crianças que experenciaram a falta dos vínculos afetivos iniciais com seus genitores/ cuidadores, pois a função dessa aliança está relacionada a uma forma de apoio vital nos primeiros meses de vida, sendo fundamental no processo de maturação e de estabelecimento de vínculos afetivos futuros (BOWLBY, 2006; WINNICCOT, 1956, 2012). Dentre as diversas consequências causadas pela falta de afetividade nos primeiros seis anos de vida, a literatura destaca os prejuízos cognitivos e afetivos.

Crianças negligenciadas, além da dor e sofrimento causados por essa má relação ainda precisam conviver com as dificuldades que as lacunas do desenvolvimento as deixou. Onde essa falta de relação de afeto também é decisiva para as suas relações social futuras.

Notadamente os indivíduos apresentam elevada dificuldade de estabelecer relacionamentos, com sérios problemas nas interações sociais, devido à tendência ao afastamento, ao isolamento e a desconfiança por medo de sofrer novos tipos de maus tratos. Sua cognição parece empobrecida, comumente indicam problemas de linguagem, de coordenação motora, além da falta de concentração, e em alguns casos a hiperatividade, prejudicando seu processo de aprendizagem e seu desempenho escolar (ACAMPARO; OLIVEIRA, 2014; GOMIDE, 2009). "Muitos dos problemas relacionados à dificuldade de aprendizagem estão relacionados à baixa autoestima, ao sentimento de ser "um patinho feio", desqualificado para realizar tarefas e ao desamor validado" (ACAMPARO; OLIVEIRA, 2014, p. 28).

Winnicott (1982, 2012) afirma que, uma das características daqueles que sofreram privação é a ausência de esperança, assim elas não possuem desejos, sonhos e nem objetivos, estando impossibilitadas de organizar um plano futuro. De acordo com Bowlby (2006), a falta de afeto e dos cuidados da figura materna e paterna modifica o comportamento e condutas dessas crianças, podendo chegar a cometer pequenos furtos, roubos, vandalismos, mentiras, agressividade, hostilidade, infringir a lei, comportamentos antissociais, entre outros. Essas atitudes têm como finalidade chamar a atenção dos seus cuidadores e/ou responsáveis para algo que está errado ou faltando, seja pela ausência de limites e/ou de afeto.

Ainda convém lembra, dando ênfase a Bowlby (2006), que alguns maustratos, principalmente os psicológicos, são mais difíceis de serem identificados por não deixarem marcas visíveis, mas que podem gerar comportamentos destrutivos e desestruturantes nos indivíduos como insegurança, fragilidade psíquica, medo, baixa autoestima, pensamento de negação, entre outros, que podem os acompanhar por toda vida. 


\section{CRIANÇAS INSTITUCIONALIZADAS E OS EFEITOS DESSA PRIVAÇÂOO}

Quando as crianças não possuem condição de permanecer em seu núcleo familiar devido a situações de média e alta complexidade na violação de seus direitos, seja por negligencia, abandono, violência e maus tratos, elas são retiradas desse ambiente por se entender que estão em situação de vulnerabilidade e de risco. Nesses casos são encaminhadas para as Casas de Acolhimentos, em que há uma equipe que passa a ser responsável pela integridade física, psíquica e social das mesmas, assim como garante o Estatuto da Criança e do Adolescente - ECA (BRASIL, 1990).

Contudo, mesmo não vivendo em situações adequadas, todo rompimento é doloroso, pois, passam a viver em um lugar novo e desconhecido. Guirado (2004, p. 204), ressalta que "mesmo que as instituições apresentem ótimas condições estruturais e ofereçam estímulos para o desenvolvimento da criança, ainda assim ela poderá ter uma "afetividade atípica"." Ou seja, a forma de se relacionar com pessoas que são desconhecidas será diferenciada de uma criança que moram com seus pais. Essa quebra de vínculo, que antes já era precário, também poderá trazer prejuízos emocionais às crianças.

\footnotetext{
Um estudo muito cuidadoso do choro e do balbucio dos bebês mostrou que os que se achavam num orfanato, desde o nascimento até os seis meses de idade, vocalizavam sempre menos do que os que viviam com famílias, podendo-se notar claramente a diferença já antes dos dois meses de idade. Este atraso na "fala" é especialmente característico da criança em instituição, em qualquer idade (BOLWBY, 2006, p.13).
}

A fala empobrecida, como também poucas expressões faciais, ou choro excessivo, acontece pela falta da pessoa de referência nos seus primeiros meses de vida, os estímulos são poucos, pois a uma grande quantidade de crianças que vivem nessas instituições, e a atenção dos cuidadores tem que ser dividida entre todas elas, em consequência acabam se tornando carentes de afetividade. Em conformidade com Pereira (2006), as crianças que são abandonadas já apresentam dificuldades em ter uma boa imagem de si, quando acontece a institucionalização há um aumento na sua carência afetiva, passando a ter como consequência uma autoestima baixa.

Santos, et al (2010), realizaram um estudo com crianças institucionalizadas entre cinco e dez anos de idade, no qual foi destacado que os infantes que foram afastadas do convivo familiar tendem a apresentarem elevada instabilidade emocional, agressividade, ansiedade, timidez, entre outros. Indicam ainda que, tanto a privação afetiva como o rompimento do vínculo familiar na fase mais importante do desenvolvimento humano podem gerar nas crianças uma distorção no desenvolvimento considerado saudável, tornando-se adultos cheios de medos, frustrações e ansiedades.

Pode-se citar outros estudos como o realizado por Cecatto (2008), com crianças institucionalizadas onde foi verificado que, para a maioria delas, a privação emocional teve como consequência a agressividade expressa em seus relacionamentos interpessoais. $\mathrm{O}$ autor acredita que essa característica pode ser vista como uma 
reivindicação dos cuidados e afeto que lhes foi tirado, pois, como os infantes ainda não sabem expressar seus sentimentos de dor e de angústia, geralmente eles são demonstrados nessas condutas, numa tentativa inconsciente de chamar a atenção para a problemática.

Tinoco e Franco (2011), salientam que a vida de crianças institucionalizadas é marcada por vários rompimentos afetivos e, consequentemente de lutos que ocorrem quando se perde algo importante, que no caso delas é a perda do convívio com seu núcleo familiar, assim como podem ser intensificados pelos constantes rompimentos de laços afetivos com as outras crianças acolhidas e com os cuidadores, o que ocasionam mais sentimentos de abandonos e de desproteção. Contudo, apesar desse aspecto prejudicial na institucionalização, se deve considerar seu caráter de acolhimento, de atender crianças cujos direitos foram negados ou violados, e que, por alguma razão, precisam ser amparadas de forma definitiva, ou temporária (até que possam retornar ao seio família), ou até mesmo, obter inserção em famílias substitutas.

Diante do exposto, o artigo em questão tem como objetivo geral analisar as consequências emocionais decorrentes da privação afetiva com uma criança em situação de acolhimento institucional, e como objetivos específicos: Identificar os principais problemas emocionais decorrentes da privação afetiva na primeira infância, através do Teste Projetivo Desenho da Família e do Teste Projetivo Fabula de Düss, como também, compreender os possíveis prejuízos (ou alterações) no desenvolvimento psicossocial da criança.

O estudo proposto se mostra relevante ao identificar quais são os principais danos emocionais causados a uma criança que experienciou a privação afetiva na primeira infância, oportunizando aprofundar a temática e contribuindo com subsídios que poderão auxiliar profissionais que atuam diretamente com crianças em situação de acolhimento institucional, como também para estudantes e profissionais de áreas afins que se interessem pelo tema e/ou trabalhem com crianças em situação de vulnerabilidade.

\section{METODOLOGIA}

Essa pesquisa tratou-se de um estudo de caso, de natureza qualitativa, exploratória. Segundo Cajueiro (2013), estudos como esses possibilitam um aprofundamento de situações e fenômenos parecidos, contribuindo para a construção de novos modelos e procedimentos, além de proporcionar maior familiaridade com o problema tendo em vista torná-lo explícito e compreensivo.

O estudo foi realizado em uma Casa de Acolhimento para crianças e adolescente, instituição coordenada pela Secretaria de Desenvolvimento Social - SEDES, vinculada a Prefeitura Municipal de João Pessoa - PB, que tem por finalidade acolher crianças e adolescente que sofreram algum tipo de negligencia ou maus tratos, sejam eles físicos, morais e/ou psicológicos, e é também voltada para a reinserção da criança e 
do adolescente na família de origem quando isto for possível ou encaminhá-las para a adoção.

Participou da pesquisa uma criança do sexo feminino, de 8 anos de idade, indicada pela Coordenação da Casa de Acolhimento, localizada na Capital de João Pessoa - PB, apresentado em seu histórico a vivência de Privação Afetiva na Primeira Infância.

Com a obtenção da aprovação do Comitê de Ética em Pesquisa se iniciou a coleta de dados, utilizando-se os seguintes instrumentos: um questionário sociodemográfico para caracterizar a criança participante desse estudo; uma entrevista semiestruturada com os responsáveis da instituição para conhecimento da historicidade da criança; os Testes Projetivos Desenho da Família e Fábula de Düss e seus devidos protocolos de correção.

As Técnicas Projetivas têm como finalidade revelar conteúdos inconscientes e traços da personalidade do sujeito. A fábula de Düss é um teste projetivo criado por Louise Düss (1986), utilizados em pessoas a partir de três anos de idade, possui por objetivo trazer conteúdos inconscientes e conscientes que facilite a investigação de traços da personalidade, como também na identificação de conflitos nas fases do desenvolvimento psicoemocional da criança, através de dez fábulas incompletas em que o participante deverá responder de forma livre e sem tempo limite. Já o teste Projetivo Desenho da Família é um teste gráfico e foi criado por Louis Corman (2003), para coletar traços da personalidade do sujeito e avaliar aspectos emocionais relacionados à família.

O projeto atendeu a Resolução 466/12, do Conselho Nacional de Saúde, que garante sigilo, anonimato e consentimento informado aos participantes e esteve em conformidade ao Estatuto da Criança e do Adolescente (ECA) - Lei Federal n ${ }^{\circ}$ 8.069/1990.

O material obtido a partir dos instrumentos utilizados foram analisados de forma qualitativa, de acordo com os manuais de cada teste projetivo, com o conteúdo mobilizado na entrevista semiestruturada, e em confluência com teoria de psicanalítica. Ressalta-se que, respeitando o sigilo ético os nomes das pessoas citadas nesse estudo foram substituídos por nomes fictícios. Assim, a seguir se realiza a apresentação do caso, relatando a história da infante participante desse estudo e de outras observações identificadas durante o processo de coleta de dados.

\section{RELATO DO CASO}

A criança Rebeca, participante deste estudo, está atualmente com 8 anos de idade, possui quatro irmãos biológicos: Pedro de 5 anos, João de 12 anos, Luana de 15 anos, e Miguel de 16 anos, estando todos em situação de acolhimento, exceto Luana que também foi acolhida, mas atualmente mora com os pais, pois se negava a permanecer na 
instituição fugindo todas as vezes que voltava para mesma. Porém, apenas o mais novo se encontra na mesma instituição que a participante, devido a faixa etária dos mesmos.

Encontra-se em situação de acolhimento desde seus seis anos de idade, estando na Instituição Jesus de Nazaré desde fevereiro de 2015. De acordo com relato da psicóloga da instituição, ela e seus irmãos foram acolhidos por estarem em situação de risco e vulnerabilidade social, com indícios de negligência, violência física e psicológica, tendo sido obrigados a realizarem trabalho infantil e, ainda sob a infante, existe a suspeita de ter sido abusada sexualmente por seu genitor. Através de escutas pontuais com os irmãos mais velhos da infante (realizada pelo Centro de Referência Especializado de Assistência Social - CREAS), não existia uma boa relação entre os filhos e seus genitores, principalmente com a figura paterna, devido à ausência de carinho, afeto, proteção e de cuidados básicos como alimentação e higiene. Há relatos desses irmãos sobre as agressões físicas e psicológicas que eram constantes sobre todos eles e sobre a genitora, perpetrados pelo pai. Apresentam indícios de que a mãe possui elevada dependência emocional do marido, defendendo as atitudes deste e seu papel de "provedor" e de “dono" da família.

Sobre o estado de saúde de Rebeca, se sabe que aos seis meses apresentou problemas cardíacos e teve que fazer uma cirurgia, tendo contado nessa época com o suporte e assistência ofertada por um casal religioso (hoje padrinhos dela) que moravam na mesma rua que os pais de Rebeca, pois os genitores abandonaram a menina enquanto essa esteve internada. A criança após ter alta passou uma temporada com esse casal a pedido dos próprios pais para que cuidassem dela até que estivesse restabelecida, porque ela apresentava um quadro de desnutrição severo, voltando meses depois para o seio familiar.

Durante a entrevista a profissional relata que quando as crianças moravam com os pais o genitor fazia atos obscenos com as crianças, as colocando para assistir filmes pornôs, no qual no discurso de um dos filhos o pai fez "xixi” no corpo de Rebeca. As agressões físicas, morais e psicológicas eram constantes, principalmente com os filhos mais velhos. A mãe por sua vez se mostrava conivente, pois em seu discurso geralmente apresentava-se como defensora do marido, afirmando inclusive que está sendo feita uma injustiça contra o mesmo. Por esses motivos, desde que as crianças entraram na instituição, não recebem visita dos pais biológicos. Por outro lado, elas foram destituídas do poder familiar, entrando no processo de adoção.

Ao chegar à instituição, a criança apresentava desnutrição, intolerância a lactose, incontinência urinária, defecava na roupa, não sabia se alimentar corretamente (sempre comendo com as mãos, chegando a sujar até mesmo os cabelos durante as refeições). Na hora do banho não permitia o toque das cuidadoras que precisavam auxiliá-la em suas dificuldades. O primeiro ano escolar de Rebeca foi após sua entrada na instituição, nesse sentido, apresenta dificuldades motoras, na linguagem, na socialização e na aprendizagem, em que até o momento a criança não está alfabetizada, denotando elevado prejuízo na leitura, na escrita e nos cálculos mais simples. 
Após um ano e dois meses de permanência da criança na instituição o casal de religioso (padrinhos da menina) entrou com o processo de adoção, no qual os mesmos tiveram que se mudar do bairro em que moravam por ameaça do pai de Rebeca após saber do pedido de adoção das crianças. O interesse na adoção era apenas para menina "Rebeca" pelo seu histórico com o casal e a existência de vínculos já constituídos. Mas, por entender que o único contato familiar que a criança tem é com o seu irmão mais novo (Pedro de 5 anos) que também se encontrava na instituição, o juiz então determinou que a guarda seria dada com a adoção dos dois. E assim foi feito! Mas, pela falta de interesse dos pais adotivos pelo irmão da Rebeca, houve rejeição por parte deles para com as crianças, em que após quase dois meses de adoção foram devolvidos à casa de acolhimento divido a dificuldade de adaptação do casal.

Atualmente a infante tem uma boa relação com as outras crianças e gosta de brincar (principalmente de pega-pega e de esconde-esconde), mas geralmente brinca sozinha em um cantinho da parede com a sua própria sobra. É uma criança muito carinhosa, amorosa e carente, apesar de ás vezes parecer bem desconfiada. Geralmente conversa e fala de cabeça baixa, evidenciando vergonha e timidez. Também demonstra pensamentos de negação contra si, sempre afirmando "não saber fazer, não saber responder, não saber desenhar" (sic).

\section{RESULTADOS}

De acordo com as respostas dadas as fábulas, no teste projetivo Fábula de Düss, Rebeca evidenciou conflitos emocionais em todas as fases do desenvolvimento infantil a partir de respostas não adaptadas, ocorrência de estados emocionais negativos de insegurança, temor e medo, assim como, fantasias destrutivas, de abandono e de rejeição.

Apresentou fixação em fases precoces do desenvolvimento, como a exemplo do estágio de separação e individualização e da fase oral, com um tipo de resposta notavelmente depressiva. Enfrenta de maneira muito sofrida a situação, a partir de conteúdos de rejeição, de abandono e de privação, resignando-se ao seu desamparo, de maneira que volta contra si mesma a agressão que não consegue direcionar para as figuras parentais.

Posiciona-se de forma passiva ao ambiente, se percebendo pouco capaz e muito desamparada, o que a leva a experimentar elevada angustia ante situações que lhe causam desconforto que, apesar de tentar manejar a situação utilizando o mecanismo de projeção, esse não se mostra eficaz, surgindo sinais de ansiedade, com bloqueio do pensamento e da verbalização. De maneira geral, “o personagem” em suas fábulas reage igualmente de maneira depressiva, sempre se submetendo as situações, incapaz de reagir de maneira agressiva contra as possíveis causas de seu desconforto.

Denota ainda um franco fracasso de suas defesas internas, com indícios de um Ego frágil e possível deteriorização psíquica. Coloca-se cansada, sem energia para reagir e para lutar, aponta sempre uma perturbação pelo o que foi vivenciado, com ênfase no 
temor a figura paterna. Em suas histórias é demonstrada a dificuldade experenciada em sua relação com as figuras parentais, principalmente a paterna, com indícios de ter sofrido violência por parte desses.

$\mathrm{Na}$ "fábula do medo" quando se pergunta "Do que ela tem medo?" a criança teve como resposta "Bicho... (“que bicho?”) Fantasma... ("o que faz?”) Assusta as pessoas... ("porque?”) Maltrata a mãe e ofilho... ("como ele é?”) Tem mâscara, cabeça, corpo e olho... ("onde ele aparece?").

No teste projetivo Desenho da Família a criança apresentou sinais de regressão como mecanismo de defesa aos seus conflitos inconscientes, demonstrando sentimentos nítidos de desarmonia, imobilidade e desamparo. Confirmando a desestrutura e falta de interação no núcleo familiar, destacando o desamor, a privação e a negligência. Em sua projeção denota sentimento de insegurança, com retraimento e submissão as frustrações colocando-se de forma passiva ante as dificuldades e os problemas sem conseguir encontrar soluções entregando-se as pressões externas com descontentamento. Apresenta fragilidade emocional devido aos diversos vínculos quebrados e que foram revividos na adoção malsucedida. Neste sentido, Rebeca se percebe rejeitada, com inadequação ao meio ambiente expressando uma elevada carência afetiva e necessidade de ser cuidada e protegida.

Observou-se elevada desvalorização das figuras parentais, em especial da figura paterna, projetando sentimentos de medo, angustias e tristeza possivelmente devido as situações de violência vividas. A criança demonstra no desenho da família sentimento de angústia com relação à figura materna expressando abandono e falta de cuidados que lhe foram negados indicando uma nítida ambivalência afetiva: sentimentos de amor e ódio por se sentir abandonada. Apresenta sinais de dependência devido à carência dos cuidados básicos que lhes foram tirados, assim como fantasias de eliminação, perca ou separação dos irmãos principalmente os mais velhos que também representavam figuras de proteção e de amor.

Indica hostilidade com relação ao ambiente restrito, com sentimento de imobilidade e desamparo. Traços dos desenhos indicam rigidez para compensar a ansiedade e insegurança. A análise do desenho também apresenta uma possível deterioração psicótica que é caracterizada pela desorganização psíquica e perca do indivíduo com a realidade, não atingindo um nível de maturidade conceitual.

\section{DISCUSSÕES}

Desde os primeiros encontros realizados com a criança, a carência de cuidados e de afeto eram nítidos, numa mistura de timidez, carinho e insegurança que foram se confirmando no decorrer dos momentos em que se estava com ela e, através das técnicas utilizadas. As dificuldades de estabelecer vínculos são características da mesma, causadas pelo medo do abandono e da rejeição (representadas na projeção das fábulas), desenvolvidas diante das inúmeras experiências negativas em sua vida afetiva, 
em que há predomínio de sentimentos de desconfiança e assim, a dificuldade ante novos relacionamentos.

Cada novo contato a remete as suas relações iniciais, despertando o medo do abandono e que no caso de Rebeca ainda foi maior devido à frustração experienciada na adoção. Autores como Mendes (2007), ver a adoção como suporte que servirá de base para constituições de laços afetivos que foram rompidos anteriormente, e na construção de valores sociais, morais e éticos. Quando essa adoção não é bem-sucedida e a criança é devolvida a instituição em que vivia, passa a tentar entender o porquê da sua devolução e pode acabar voltar para si à culpa de mais um abandono. Esse novo abandono fragiliza ainda mais a sua autoestima podendo influenciar na sua relação interpessoal e intrapessoal.

Para tanto, verifica-se através do material apresentado pela criança que essa sofreu maus tratos com privações e punições severas num ambiente inadequado e austero indicando elevada desvalorização das figuras parentais. O fator ambiental é determinante para definir se essa criança será saudável psiquicamente ou não. Essas consequências são causadas por falhas nesse ambiente e elas vão depender de como e quando acontecem.

Winnicott (1960,1983, p.45-46), cita dois momentos primordiais nessa fase a "dependência absoluta" e a "dependência relativa". A primeira ocorre no início da vida do bebê em que o afeto é demonstrado por meio do "holding físico", ou seja, a criança depende integralmente da mãe. Quando são inseridas falhas severas nessa fase pode ocorrer uma interrupção do amadurecimento, sendo representadas mais tarde como uma deficiência mental, esquizofrenia infantil, tendo uma predisposição para uma doença mental. Mas, se essa fase for bem elaborada o bebê passará a não ter mais uma dependência absoluta e sim uma dependência relativa, em que já não depende totalmente de sua mãe. Como na primeira fase, se as falhas ambientais não acontecerem de forma saudável pode-se também ter consequências na criança havendo uma predisposição a distúrbios afetivos e tendência antissocial.

Sobre essas falhas, destaca-se que a autoestima, a segurança e a confiança de uma criança estão totalmente interligadas com a relação vivenciada com os seus genitores e que vão ser determinantes na sua formação psicossociais (PEREIRA; ZANONI; MOSER, 2007). Essa capacidade de estabelecer vínculos afetivos conforme Bowlby (2015), vai depender dessas experiências com os cuidadores primários. Experiências essas também citadas por Sptiz (1980) são fundamentais para o amadurecimento psicológico e a capacidade de estabelecer vínculos futuros. Bowlby (2006) nomeia de "teoria do apego" a relação afetiva estabelecida entre a criança e o seu cuidador primário, onde são criadas estratégias para se manter próximos ao outro, como formas de carinho e cuidados.

É importante ressaltar que nos desenhos realizados em nossos encontros a criança expressava elevada tristeza e sofrimento, destacando traços que caracterizam possíveis abusos e negligencia através de figuras sem cor, geralmente com traço dos 
desenhos desfragmentados, que não demonstravam vida e nem alegria, numa projeção dos seus próprios conflitos internos. Cerqueira (2012), cita em seu estudo que a criança se utiliza dos desenhos que é uma forma de comunicação, um recurso para expressar suas experiências, vivencias e sentimentos recalcados ou ocultos e que estão diretamente ligados ao seu ambiente familiar ou por que não dizer institucional. Os conteúdos ali representados são projeções conscientes e principalmente inconscientes, ou seja, desconhecidos para aqueles que os projetam. $\mathrm{O}$ desenho nos permiti identificar tudo aquilo que não é verbalizado e é a partir dele que iremos investigar todos os conflitos que permeiam a vida da criança sejam eles relacionados a sua afetividade, fantasias ou fantasmas.

Diante desta problemática, conflitos emocionais também foram identificas no teste da Fábula, tendo sido apresentadas respostas significativas em todas as fases do desenvolvimento infantil, principalmente na fase oral. Freud (1905, 1996), destaca que essa é a primeira fase do desenvolvimento psicossexual, uma das mais importantes do desenvolvimento infantil, em que o objeto de prazer da criança é o seio da mãe, e através da amamentação é estabelecido um vínculo afetivo entre a mãe e o bebê, representando uma troca de carinho e de amor, esse contato dá início aos sentimentos arcaicos, que unem o sujeito a sua família.

Quando essa fase primária do desenvolvimento não é bem elaborada de acordo com Winnicott (1958, 2000), a criança regride, ocorrendo uma fixação em que pode ser vista como um bloqueio no seu desenvolvimento. Esse bloqueio interrompe o amadurecimento da criança trazendo para si dificuldades não somente de cunho cognitivo ou afetivo, mas problemas relacionados ao seu desenvolvimento psíquico, no qual o sujeito perde o contato com a realidade. Essas falhas na estruturação do desenvolvimento podem ser denominadas de psicose. Apesar do cérebro se manter intacto, a psicose é vista como um distúrbio psicológico que ocorre nas fases primárias do desenvolvimento emocional, representando uma ameaça nas defesas organizadas do sujeito, causando uma ruptura com a realidade (WINNICOTT, 1960, 2013). Crianças que apresentam esse transtorno geralmente possuem uma forte ambivalência nas suas manifestações afetivas, às vezes assumem rapidamente um contato afetivo, e rapidamente apresenta sentimento de medo e angustia pela ameaça de sofrimento que o outro pode lhe proporcionar. Essa desarmonia de investimentos pode prejudicar seu desenvolvimento cognitivo e, consequentemente ter uma linguagem empobrecida (AJURRIAGUERRA; MARCELLI, 1998).

Apesar da empatia estabelecida em todos os encontros, as dificuldades citadas acima eram nítidas. A criança teve dificuldades em olhar nos olhos, como também apresenta uma linguagem empobrecida e de difícil compreensão. Não sabe ler nem escrever, mas sempre representa nomes através de desenhos gráficos. Essas dificuldades se refletem nas relações sociais da criança, pois a vergonha e o medo causados pela dificuldade de aprendizagem a levará ao afastamento de outras crianças e das pessoas, 
se tornando um sujeito com comportamentos antissocial (WINNICOTT, 1956, 2012).

Também pode ser observado que Rebeca tem um desenvolvimento físico diferente de outras crianças da mesma idade com estatura e peso notoriamente abaixo da média, estando possivelmente relacionados ao quadro de desnutrição apresentado desde quando era um bebê, e quando deu entrada na instituição, causados pela falta de cuidados básicos em sua alimentação orgânica e emocional. Ajurriaguerra e Marcelli (1998), cita que é possível observar em crianças que sofreram maus tratos ou negligencia que o seu crescimento é diferenciado, acontece de forma irregular, podendo se tornar uma pessoa vulnerável tanto fisicamente, como emocionalmente.

Vale destacar ainda que, na aplicação dos testes projetivos Rebeca se mostrou bastante ansiosa e inquieta havendo resistência na elaboração das respostas das fábulas, em que por duas vezes quis encerrar o teste confirmando vários conflitos relacionados à sua fase de desenvolvimento como também ao seu histórico de vida. A resistência assim como a racionalização são argumentos utilizados para distorcer ou evitar toda angústia inconsciente e sofrimento que aquela problemática causa no infante, tornandose suportável (MEZAN, 2013).

Em seu discurso diz "não gosto de beijos e abraços, de briga e de quem bate nos outros, porque isso faz mal” (sic), essas representações indicam experiências traumáticas que já foram vivenciadas pela criança em seu núcleo familiar, se projeta como telespectadora e ao mesmo tempo protagonista de discussões, brigas e agressões dentro deste contexto, com relatos bastante claros e significativos. Em alguns momentos demonstrava resistência, tendo como respostas "não sei, esqueci, não vou falar" (sic), ocasiões em que se sentia mobilizada diante desses conflitos, que foram projetados no Desenho da Família e na Fábula de Duss, denotando desvalorização e uma valência negativa, predominantemente ao se referir a figura paterna, com sentimentos de temor, medo, angústia, raiva e tristeza.

Em estudo realizado por Pelisoli, Teodoro e Dell’Aglio (2007), com crianças que sofreram maus tratos e abusos, foram identificados que na maioria dos casos, as agressões eram realizadas por pessoas próximas da família, sendo parentes ou o próprio pai. As consequências dessas agressões podem causam um forte desestrutura no infante e em todo núcleo familiar. Provocando não somente um rompimento dos vínculos e laços afetivos, mas também sentimentos de medo e culpa, dando início a um processo de isolamento e agressividade no infante.

De maneira geral, foi identificado na criança conflitos relacionado às fases do desenvolvimento psicossexual e a desestruturação e disfunção familiar que repercute em sua capacidade de se relacionar, de aprender e de confiar nas pessoas. Seu estado emocional é negativo, apresenta também fantasias destrutivas voltadas para as figuras parentais em que posteriormente volta para si, pois todo ato de negligencia e principalmente a falta de afeto e abandono causa na criança um forte sentimento de raiva e angustia, mas por não saber e até mesmo ser impossibilitada de expressar esses 
conflitos a criança passa a acreditar que todos os problemas que lhe são ocorridos como o abandono é culpa sua, que fez algo errado, que lhe falta algo, ou onde errou para que seus pais não lhe amem mais, como punição por sentir raiva.

Segundo Freud (1905, 1996), esses fantasmas são representações da angustia infantil, diretamente ligada com falta da pessoa amada e, também, a culpa gerada na criança por sentir raiva desse objeto de amor e não conseguir representá-las. Bairros et al (2011), afirma que as ausências da relação parental na fase mais importante do desenvolvimento podem deixar fortes marcas no inconsciente das crianças, acarretando prejuízo no que diz respeito ao seu convívio social, inclusive o rompimento dessa relação traz consequências para a saúde mental do infante.

Em sua teoria Winnicott (1982, 2012), cita que a mãe suficientemente boa será a base para formação da personalidade saudável da criança, como também, é de suma importância na constituição do ego de seu filho. A partir desta construção, o infante passa a ser capaz de elaborar suas próprias expectativas e memórias, aprendendo a formar seu próprio Eu. A falta dessa relação na constituição psíquica da criança impede que seu desenvolvimento ocorra de maneira adequada se tornando passiva com relação aos aspectos pessoais e ao ambiente.

Spritz (1980), em um dos seus estudos relata que problemas como os distúrbios emocionais e a carência de afeto nas crianças podem ser provocados pela incapacidade ou falha da genitora em ser uma mãe suficientemente boa, em que são evidentes perturbações psicológicas apresentadas por essas crianças.

As dificuldades de reagir perante as suas problemáticas e ao mundo são causas da sua incapacidade de autodefesa sendo hostil com relação ao ambiente que vive. Seu cansaço e baixa autoestima a impede de reagir. Todos esses conflitos estão diretamente relacionados com o seu núcleo familiar. Bowlby (2006), afirma que a separação e privação prolongada da criança com sua cuidadora primária (a mãe ou substituta) na primeira infância pode causar danos irreversíveis a estruturação da personalidade, gerando também, dificuldades para se relacionar, criar vínculos afetivos e uma forte inibição de sentimentos, ou seja, essa relação é determinante para toda a vida do sujeito.

O bloqueio de pensamentos e verbalização nas suas projeções confirmou as dificuldades vivenciadas na sua primeira infância. Essa falta de estímulos e valorização da criança fragiliza o seu Ego, contribuindo para o fracasso das suas defesas internas. A regressão as fases mal elaboradas do desenvolvimento podem gerar rejeições como autodefesa e até as atitudes violentas, sendo essas características pertencentes a crianças que passaram por algum trauma ou por acontecimentos que as prejudicaram. Assim, a maternagem não vivenciada de forma adequada pode causar transtornos emocionais e do desenvolvimento da criança (GLENN, 1996).

Alguns outros distúrbios podem ser destacados, como as dificuldades apresentadas pela infante no controle das fezes e da urina, nomeados de Enurese e Ecoprese. Alguns fatores estão relacionados a esses distúrbios, como o neurofisiológico, o social, e o emocional, dando destaque a relação familiar e psicoafetiva (AJURRIAGUERRA; 
MARCELLI, 1998). Winnicott (1950, 2013), vem afirmar que crianças que ainda urinam de forma irregular mesmo já grandinha, possivelmente estão em busca do colo da mãe, ou seja, da afetividade e cuidados existentes nas primeiras fases do desenvolvimento.

Em pesquisas realizadas com crianças que sofreram ou sofrem a falta de cuidados e estímulos básicos, como também a violência familiar seja ela de ordem física, psicológica ou sexual, foi dado destaque há várias problemáticas, citando os físicos, como a desnutrição e baixo peso, as falhas cognitivas e as dificuldades emocionais como o isolamento social, e a baixa autoestima podendo levar a depressão (REICHENHEIN, 1999). Delanez (2012), destaca que esses descuidos, os maus tratos, a violência física, psicológica e principalmente a sexual deixarão marcas na vida da criança que perdurará por tudo sua existência.

\section{CONCLUSÃO}

O presente estudo buscou identificar como as falhas das figuras parentais podem trazer prejuízos ao desenvolvimento de uma criança principalmente em seus primeiros anos de vida, no que se refere aos campos social, emocional, cognitivo e biológico. Para tanto, procurou-se compreender o que é a privação de afeto, como ela acontece, e as suas consequências como causa de vários problemas relacionados à primeira infância.

Teóricos citados neste estudo quando relatam sobre as implicações dessa negligência sejam elas pela falta total de afeto ou até mesmo pela falta de cuidados considerados básicos como a alimentação e higiene, no faz perceber o quanto a qualidade familiar é importante para a estruturação do ser em todas as fases de sua vida. Apontando para que o sujeito tenha um crescimento considerado saudável é preciso que tenha uma infância tranquila, acompanhada de cuidados, carinho e afeto.

A Privação Afetiva causada pelo abandono e por essas negligências podem trazer danos irreversíveis a vida de uma criança, podendo destacar a importância fundamental do núcleo familiar e principalmente a participação materna nesse processo. A primeira infância (de zero a sete anos) pode ser considerada a fase mais frágil e primordial que determinará o sujeito e sua personalidade ao longo de toda sua vida.

Esses prejuízos foram confirmados através dos resultados obtidos nesse estudo, em que foi identificado que a má qualidade dessa relação de afeto e nos cuidados prejudicou o desenvolvimento da criança desse estudo em vários aspectos, como por exemplo, o cognitivo devido à falta de estímulos que é empobrecido gerando dificuldades na fala e na aprendizagem. No biológico, foi destacado o atraso no seu desenvolvimento físico, como também vários problemas de saúde. Por fim, podemos citar consequências no campo emocional em que a criança tende a ter uma autoestima baixa, seu semblante é triste e frágil. Apresenta-se uma criança insegura com dificuldades nas interações sociais, chegando a usar o medo e o isolamento como forma de se proteger de novos maus tratos e sofrimento. É hostil ao ambiente, chegando a afetar também o desenvolvimento da personalidade. 
A partir de tais compreensões acerca dos efeitos em crianças que sofreram privação afetiva destacadas nessa pesquisa faz-se necessário um olhar de forma especial voltados para o seu acolhimento, seja por seus cuidadores, responsáveis legais, ou até mesmo pelos órgãos públicos, dando suporte para que os campos que foram fragmentados como os laços afetivos, possam ser desenvolvidos da maneira mais saudável possível.

Diante de tais afirmativas, esse estudo se tornou relevante, pois traz uma reflexão sobre a importância da relação de afeto e cuidados com as crianças, e as consequências pela falto do mesmo, principalmente as que estão na primeira infância, fase determinante para o desenvolvimento da personalidade do sujeito.

No que se remete ao desenvolvimento infantil, a psicologia possibilita esclarecimentos acerca deste, pois os estudos nesta área, agregam uma maior compreensão sobre o mesmo, a fim de fortalecer os laços familiares e, por conseguinte promover a promoção de saúde no que se remete aos cuidados com as crianças. Essa temática também oportuniza esclarecimentos aos profissionais e educadores sociais que atuam nas instituições de acolhimento, para que identifiquem as dificuldades enfrentadas por essas crianças e as auxiliem no processo de desenvolvimento, de estruturação e de fortalecimento de vínculos afetivos.

Dessa forma, assim como a pesquisa em questão, vários teóricos abordam esse tema, mas diante de sua complexidade fazem-se necessários estudos para que possam sempre se capacitar e terem subsídios, principalmente aos que lidam com essas crianças negligenciadas, como também buscar novos dados e perspectivas que contribuam com os resultados aqui obtidos, possibilitando um olhar mais humanizado às crianças que sofrem com a falta de cuidados afetivos básicos e tão necessários.

\section{REFERÊNCIAS}

ACAMPARO, Beatriz; OLIVEIRA, Silva De. SEM PALMADAS. Revista Psique Ciência E Vida. São Paulo, v. VIII, n. 103, p. 24-30, junho, 2014.

AJURIAGUERRA, Julian de; MARCELLI, Daniel. Manual de Psicopatologia da Infância de Ajuriaguerra. 5. Ed. Porto Alegre: ArtMed, 1998.

BAIRROS, Jaqueline de. et al. Infância e adolescência: a importância da relação afetiva na formação e desenvolvimento emocional. XVI Seminário Interinstitucional de ensino, pesquisa e extensão, XIV Mostra de Iniciação Científica, IX Mostra de Extensão. Dias 04 a 06 de outubro de 2011. Cruz Alta: UNICRUZ, 2011. Disponível em: <http://www.unicruz.edu.br/seminario/artigos/ humanas/INF\%C3\%82 NCIA\%20E\%20ADOLESC\%C3\%8ANCIA\%20A\%20 IMPORT\%C $3 \% 82$ NCIA $\% 20 D A \% 20$ RELA $\%$ C $3 \% 87 \%$ C3\%83O\%20AFETIVA\%20 NA \%20FORMA \%C $3 \% 87 \% \mathrm{C} 3 \% 83 \mathrm{O} \% 20 \mathrm{E} \% 20$ DESENVOLVIMENTO \%2oEMOCIONAL.pdf>. Acesso em: 18 de Março de 2017. 
BENHAIM, Michèle. O materno e a delinquência. Ágora (Rio J.), Rio de Janeiro , v. 11, n. 1, p. 9-16, junho, 2008. Disponível em: < http://dx.doi.org/10.1590/S1516$14982008000100001>$. Acesso em: 18 de março de 2017.

BORGES, Maria Luiza Soares Ferreira. Função materna e função paterna: suas vivências na atualidade. 2005. 148 f. Dissertação (Mestrado em Psicologia Aplicada). Universidade Federal de Uberlândia. Uberlândia, 2005. Disponível em: <http:// www.webposgrad.propp.ufu.br/ppg/producao_anexos/014_Maria\%20Luiza\%20 Soares\%20Ferreira\%20Borges.pdf> . Acesso em: 15 de Agosto de 2016.

BOWLBY, John. Formação e rompimento dos laços afetivos. 5. ed. São Paulo: Martins Fontes, 2015.

BOWLBY, John. Cuidados maternos e saúde mental. 5. ed. São Paulo: Martins Fontes, 2006.

BRASIL, 1990. Estatuto da Criança e do Adolescente - ECA. 13. ed. Brasília: Câmara, 2015. 117 p.

CAJUEIRO, Roberto Liana Pimentel. Manual de Elaboração de Trabalhos Acadêmicos: Guia prático do estudante. Rio de Janeiro: Vozes, 2013.

CECATTO, Grasiela Maria. Comportamento agressivo e aspectos psicodinâmicos em crianças abrigadas. 2008. 91 f. Dissertação (Mestrado em Psicologia Clínica). Faculdade de Psicologia da Pontifícia Universidade Católica do Rio Grande do Sul. Porto Alegre, 2008. Disponível em: <http: //repositorio.pucrs.br/dspace/ handle/10923/4968>. Acesso: O1 de outubro 2016.

CERQUEIRA. Luana, Chaves, De. Manifestações Do (In) Consciente Infantil, Através Do Desenho E História De Vida, No Contexto Escolar: Uma Possível Interpretação Psicanalítica. 2012. 88 f. Artigo (Licenciada Em Pedagogia). Universidade De Brasília Faculdade De Educação. Brasília, 2012. Disponível Em: < http://bdm.unb.br/bitstream/10483/5019/1/2012_LuanaChavesdeCerqueira.pdf>. Acesso Em: 23 De Abril De 2017.

CORMAN, Louis. O teste do desenho da família. São Paulo: Casa do Psicólogo, 2003.

DELANEZ, Geovana Oliveira. A violência intrafamiliar e suas consequências no desenvolvimento da criança. 2012. 29 f. Artigo (Bacharel em Direito) Faculdade de Direito da Pontifícia Universidade Católica do Rio Grande do Sul. Rio Grande do Sul, 2012. Disponível em: <http://www3.pucrs.br/pucrs/files/uni/poa/direito/ graduacao/tcc/tcc2/trabalhos2012_1/geovana_delanez.pdf $>$. Acesso em: 13 de Abril de 2017. 
DÜSS, Louisa. Fábulas de Düss: O método das fábulas em psicanálise infantil. São Paulo: Casa do Psicólogo, 1986.

FREUD, Sigmund (1905). Três Ensaios Sobre A Teoria Da Sexualidade. Edição StandartBrasileira das Obras Psicológicas Completas. v. V, Rio de Janeiro: Imago, 1996.

GOMIDE, Paula Inez Cunha. Pais presentes, pais ausentes: regras e limites. 9. ed. Rio de Janeiro: Vozes, 2009.

GUIRADO, Marlene. Instituição e relações afetivas: O vínculo com o abandono. São Paulo: Casa do Psicólogo, 2004.

GLENN, Jules. Psicanálise e Psicoterapia de Crianças. Porto Alegre: Artes Médicas, 1996.

MENDES, Cynthia Lopes Peiter Carballido. Vínculos e rupturas na adoção: Do abrigo para a família adotiva. 2007. 217 f. Dissertação (Mestrado em psicologia clínica). Instituição de psicologia, Universidade de São Paulo. São Paulo, 2007. Disponível em: <file://C:/Users/VANESSA/Downloads/Mendes_Mestrado.pdf>. Acesso em: 17 de Abril de 2017.

MEZAN, Renato. Freud: A trama dos conceitos. 5. Ed. São Paulo: Perspectiva, 2013.

PELISOLI, Cátula.; TEODORO, Maycoln Lêoni Martins.; DELL’AGLIO, Débora Dalbosco. A percepção de família em vítimas de abuso sexual intrafamiliar: estudo de caso. Arquivos Brasileiros de Psicologia, PePSIC. v. 59, n.2, p. 256-269. Rio de Janeiro. Outubro, 2007. Disponível em: <http://pepsic.bvsalud.org/pdf/arbp/v59n2/ v59n2a14.pdf>. Acesso em: 12 de Abri de 2017.

PEREIRA, Cristina dos Santos.; ZANONI, Décio,; MOSER, Ana Maria. Formação do Autoconceito e da Auto-estima em Crianças Institucionalizadas. in: CARVALHO, Maria Cristina Neiva de; MIRANDA, Vera Regina Miranda. (orgs). Psicologia Jurídica: Temas de Aplicação I. Curitiba: Juruá, 2007.p. 43-60.

PEREIRA, Eliane Vecchi. A voz da criança institucionalizada: representações sociais de família e abrigo. 2006. 170 f. Tese (doutorado em serviço social) Universidade Estadual Paulista, Faculdade de História, Direito e Serviço Social, São Paulo, 2006. Disponível em: <http://hdl.handle.net/11449/106109>. Acesso em: 14 de Abril de 2017. 
REICHENHEIM, Michael .; HASSELMANN, Maria Helena.; MORAES, Claudia Leite. Consequências da violência familiar na saúde da criança e do adolescente: contribuições para a elaboração de propostas de ação. Ciência \& Saúde Coletiva. Rio de Janeiro. v. 4, n. 1, p. 109-121, 1999. Disponível em: <http://www.scielo.br/ $\mathrm{pdf} / \% \mathrm{OD} / \mathrm{csc} / \mathrm{v} 4 \mathrm{n} 1 / 7134 . \mathrm{pdf}>$. Acesso em: 12 de Abril de 2017.

SANTOS, Benedito Carlos Alves dos et al . Características emocionais e traços de personalidade em crianças institucionalizadas e não institucionalizadas. Boletim de Psicologia. PePSIC, São Paulo, v. 60, n. 133, p. 139-152, dezembro, 2010 . Disponível em <http://pepsic.bvsalud.org/scielo.php?script=sci_arttext\&pid=SoOo659432010000200002\&lng=pt\&nrm=iso >. Acesso em: 25 de Setembro de 2016.

SPITZ, René Arpad. O primeiro ano de vida: um estudo psicanalítico do desenvolvimento normal e anômalo das relações objetais. Tradução Erothildes Millan Barros da Rocha. 2. Ed. São Paulo: Martins Fontes, 1980.

TINOCO, Valéria.; FRANCO, Maria Helena Pereira. O luto em instituições de abrigamento de crianças. Estudos de Psicologia (Campinas). Campinas, v. 28, n. 4, p. 427-434, Dezembro, 2011. Disponível em: <http://www.scielo.br/pdf/estpsi/ v28n4/03.pdf>. Acesso em: 02 de outubro de 2016.

UNESCO-Organização das Nações Unidas para a Educação, a Ciência e a Cultura. Bases sólidas: Educação e cuidados na Primeira Infância, Relatório Conciso. Brasília, 2007. Disponível em: <http://unesdoc.unesco.org/images/00 14/001477/147785por. pdf $>$. Acesso em: 13 de agosto de 2016.

UNICEF - Fundo Das Nações Unidas Para A Infância. Os primeiros seis anos de vida. São Paulo: Revisão e edição: B\&C, 2001. Disponível em: <http://www.unicef. org/brazil/pt/SIB1.pdf>. Acesso: 16 de agosto de 2016.

WINNICOTT, Donald Woods. (1960). A família e o desenvolvimento individual. 4. ed. São Paulo: Martins Fontes, 2013. (1950). A família e o desenvolvimento individual. 4. ed. São Paulo: Martins Fontes, 2013. . (1956). Privação e Delinquência. 5. ed. São Paulo:

Martins Fontes, 2012. (1958). Da Pediatria à Psicanálise. 2. ed. Rio de Janeiro: Imagino, 2000. 
. (1960). O Ambiente e os Processos de Maturação: estudos sobre a teoria do desenvolvimento emocional: Estudos sobre a teoria do desenvolvimento emocional. Porto Alegre: Artmed, 1983.

2012.

(1982). A Criança e o Seu Mundo. Porto Alegre: LTC, 